\title{
A descriptive study of Lewy body dementia with functional imaging support in a Chinese population: a preliminary study
}

\author{
YF Shea *, LW Chu, SC Lee
}

\section{A B S T R A C T}

Introduction: Lewy body dementia includes dementia with Lewy bodies and Parkinson's disease dementia. There have been limited clinical studies among Chinese patients with Lewy body dementia. This study aimed to review the presenting clinical features and identify risk factors for complications including falls, dysphagia, aspiration pneumonia, pressure sores, and mortality in Chinese patients with Lewy body dementia. We also wished to identify any difference in clinical features of patients with Lewy body dementia with and without an Alzheimer's disease pattern of functional imaging.

Methods: We retrospectively reviewed 23 patients with Lewy body dementia supported by functional imaging. Baseline demographics, presenting clinical and behavioural and psychological symptoms of dementia, functional and cognitive assessment scores, and complications during follow-up were reviewed. Patients with Lewy body dementia were further classified as having an Alzheimer's disease imaging pattern if functional imaging demonstrated bilateral temporoparietal hypometabolism or hypoperfusion with or without precuneus and posterior cingulate gyrus hypometabolism or hypoperfusion.

Results: The pre-imaging accuracy of clinical diagnosis was $52 \%$. In $83 \%$ of patients, behavioural and psychological symptoms of dementia were evident. Falls, dysphagia, aspiration pneumonia, pressure sores, and death occurred in 70\%, 52\%, $26 \%, 26 \%$, and $30 \%$ of patients, respectively with
$0.17,0.18,0.08$, and 0.10 . Patients with aspiration pneumonia compared with those without were more likely to have dysphagia ( $100 \%$ vs $35 \% ; \mathrm{P}=0.01)$. Deceased patients with Lewy body dementia, compared with alive patients, had a higher (median [interquartile range]) presenting Clinical Dementia Rating score (1 [1-2] vs 0.5 [0.5-1.0]; $\mathrm{P}=0.01$ ), lower mean ( \pm standard deviation) baseline Barthel index (13 \pm 7 vs $18 \pm 4 ; \mathrm{P}=0.04)$, and were more likely to be prescribed levodopa ( $86 \%$ vs $31 \%$; $\mathrm{P}=0.03$ ). Patients with Lewy body dementia with an Alzheimer's disease pattern of functional imaging, compared with those without the pattern, were younger at presentation (mean \pm standard deviation, $73 \pm 6$ vs $80 \pm 6$ years; $\mathrm{P}=0.02$ ) and had a lower Mini-Mental State Examination score at 1 year $(15 \pm 8$ vs $22 \pm 6$; $\mathrm{P}=0.05)$.

Conclusions: Falls, dysphagia, aspiration pneumonia, and pressure sores were common among patients with Lewy body dementia. Those with an Alzheimer's disease pattern of functional imaging had a younger age of onset and lower 1-year Mini-Mental State Examination score.

\section{Hong Kong Med J 2017;23:222-30}

DOI: $10.12809 / \mathrm{hkmj} 166023$

YF Shea *, MRCP(UK), FHKAM (Medicine)

LW Chu, MD, FRCP

SC Lee, BHS(Nursing)

Geriatrics Division, Department of Medicine, Queen Mary Hospital, Pokfulam, Hong Kong

* Corresponding author: elphashea@gmail.com

New knowledge added by this study

- Behavioural and psychological symptoms of dementia were present in $83 \%$ of patients with Lewy body dementia (LBD).

- Falls, dysphagia, aspiration pneumonia, and pressure sores were common complications in LBD patients.

- Chinese LBD patients with an Alzheimer's disease pattern of functional imaging had a younger age of onset and lower 1-year Mini-Mental State Examination score.

Implications for clinical practice or policy

Such information is useful in the formulation of a management plan, including advance care planning, for Chinese LBD patients.

\section{Introduction}

Lewy body dementia (LBD) includes dementia with Lewy bodies (DLB) and Parkinson's disease dementia (PDD). ${ }^{1}$ Pathological hallmarks of LBD include $\alpha$ - synuclein neuronal inclusions (Lewy bodies and Lewy neurites) with subsequent neuronal loss. ${ }^{1}$ The difference between DLB and PDD lies in the sequence of onset of dementia and parkinsonism, 
although syndromes and pathological changes become similar with progression..$^{1,2}$ Thus, they are regarded as a continuum instead of two separate entities. In western studies, approximately $10 \%$ to $15 \%$ of patients with dementia had DLB. ${ }^{1}$ In contrast, only $3 \%$ of 1532 patients with dementia followed up at the memory clinic of Queen Mary Hospital in Hong Kong had LBD (unpublished data). It is likely that LBD remains under-recognised among the Chinese population.

Compared with autopsy, sensitivity and specificity for clinical diagnosis of DLB have been reported to be $32 \%$ and $95 \%$, respectively. ${ }^{1}$ In our memory clinic, $50 \%$ of DLB patients were initially misdiagnosed (mostly as Alzheimer's disease [AD] in $75 \%$ of cases). ${ }^{3}$ There has been only one case series of 35 Chinese DLB patients and diagnosis was based mainly on clinical criteria. ${ }^{4}$ The presence of occipital hypometabolism on $\left[{ }^{18} \mathrm{~F}\right]$-2-fluoro-2-deoxy-Dglucose positron emission tomography $\left({ }^{18}\right.$ FDG-PET) has a sensitivity of $90 \%$ and specificity of $71 \%$ to $80 \%$ in differentiating $\mathrm{AD}$ and DLB patients. ${ }^{5}$

Pathologies of AD are common in DLB patients; $35 \%$ of patients with Parkinson's disease fulfil the pathological diagnostic criteria of $A D$, while deposition of amyloid plaques is present in approximately $85 \%$ of DLB patients. ${ }^{6}$ A meta-analysis revealed a positive amyloid scan in $57 \%$ and $35 \%$ of patients with DLB and PDD, respectively. ${ }^{5} \mathrm{~A}$ higher cortical amyloid burden has been associated with greater cortical and medial temporal lobe atrophy in LBD patients. ${ }^{6}$ Significant cortical amyloid burden may accelerate the cognitive decline in LBD patients, suggesting the possibility of a synergistic contribution of AD pathologies to LBD dementia. ${ }^{6}$ On ${ }^{18} \mathrm{FDG}$ PET, apart from bilateral occipital hypometabolism, some LBD patients also demonstrate an AD pattern of hypometabolism, ie temporoparietal, posterior cingulate gyrus or precuneus hypometabolism (Fig). ${ }^{7}$ In a recent study comparing 12 patients with $\mathrm{DLB}$ and an AD pattern of hypometabolism on ${ }^{18}$ FDG-PET with 11 patients with DLB and no AD pattern of hypometabolism, the former had a higher prevalence of visual hallucinations and extracampine hallucination. ${ }^{7}$ As far as we are aware, an $\mathrm{AD}$ pattern of functional imaging has not been studied in Chinese patients with DLB.

In contrast with $\mathrm{AD}$, the clinical features of patients with DLB are unfamiliar to the general public. In a recent study that involved 125 carers of LBD patients, $82 \%$ to $96 \%$ expressed a wish to have information and support about visual hallucinations, changes in the brain and the body, and ways to cope with behavioural changes. ${ }^{8}$ Unfortunately clinical studies of LBD among the Chinese population are limited and none has examined the longterm outcomes of LBD, including falls, dysphagia, aspiration pneumonia, pressure sores, mortality,

\section{華籍人口中路易氏體失智症與功能成像的描述性 研究：初步研究 \\ 佘日峰、朱亮榮、李瑞貞}

引言：路易氏體失智症（LBD）包括散播性路易氏體失智症和帕金森 病失智症。有關LBD華籍患者的臨床研究有限。本研究探討LBD患者 的臨床特徵, 以及找出併發症的風險因素, 包括跌倒、吞嚥困難、吸 入性肺炎、裖艙和死亡率。我們亦希望找出LBD患者的臨床特徵在有 或無阿爾茨海默氏病 $(\mathrm{AD})$ 典型成像的情況下的差異。

方法：我們回顧分析了23名LBD患者, 他們均有功能成像紀錄。回 顧資料包括基線人口統計學資料、患者的臨床和行為和心理症狀、功 能和認知評估得分, 以及隨訪期間出現的併發症。如果LBD患者的 功能成像顯示雙側䫓頂葉代謝減退和血液灌流不足 (不論有或無楔前 葉), 和扣帶回後部代謝減退和血液灌流不足, 便會被進一步分類為 具有 $\mathrm{AD}$ 成像模式。

結果：成像前的臨床診斷精確度為 $52 \% \circ 83 \%$ 的LBD患者有明顯的 失智症合併精神及行為症狀。患者中的跌倒、吞嚥困難、吸入性肺 炎、裖瘡和死亡率依次為 $70 \%$ 、 $52 \%$ 、26\%、26\%和30\%, 相應的事 件發生率依次為每人年 $0.32 、 0.17 、 0.18 、 0.08$ 和 0.10 。有吸入性 肺炎比沒有此症的患者較有可能同時有吞嚥困難（100\%比 $35 \%$; $\mathrm{P}=0.01$ ）。LBD死亡患者比生還的患者有較高的臨床失智評分（中 位數 [四分位數範圍] : 1 [1-2]比 $0.5[0.5-1.0] ; \mathrm{P}=0.01)$ 、較低的平 均Barthel指數 $(13 \pm 7$ 比 $18 \pm 4 ; \mathrm{P}=0.04)$, 以及更有可能獲左旋多 巴處方 $(86 \%$ 比 $31 \% ; \mathrm{P}=0.03)$ 。具有 $\mathrm{AD}$ 功能成像模式的LBD患者 比沒有此模式的患者發病年齡較低 (平均值 \pm 標準偏差, $73 \pm 6$ 歲比 $80 \pm 6$ 歲 $; P=0.02)$, 並且其 1 年簡易智能狀態檢查得分較低（15 \pm 8 比 $22 \pm 6 ; \mathrm{P}=0.05$ )。

結論：LBD患者經常出現跌倒、吞嚥困難、吸入性肺炎和裖㾫。那些 具有AD功能成像模式的患者發病年齡較低, 其 1 年簡易智能狀態檢查 得分亦較低。

and behavioural and psychological symptoms of dementia (BPSD).

Based on a review of the clinical records of all LBD patients followed up in our memory clinic, the current study aimed to review the presenting clinical features and identify risk factors for longterm outcomes including falls, dysphagia, aspiration pneumonia, pressure sores, and mortality in Chinese patients with LBD. It was hoped that this would provide useful clinical information for carers of such patients. We also wished to identify any difference in clinical features of LBD patients with and without an AD pattern of functional imaging. We hypothesised that LBD patients with an AD pattern of functional imaging would have a young age at presentation or diagnosis due to concomitant AD pathologies.

\section{Methods}

This was a retrospective case series of Chinese LBD patients. The case records of Chinese patients with LBD who attended a memory clinic at Queen Mary Hospital between 1 January 2007 and 31 


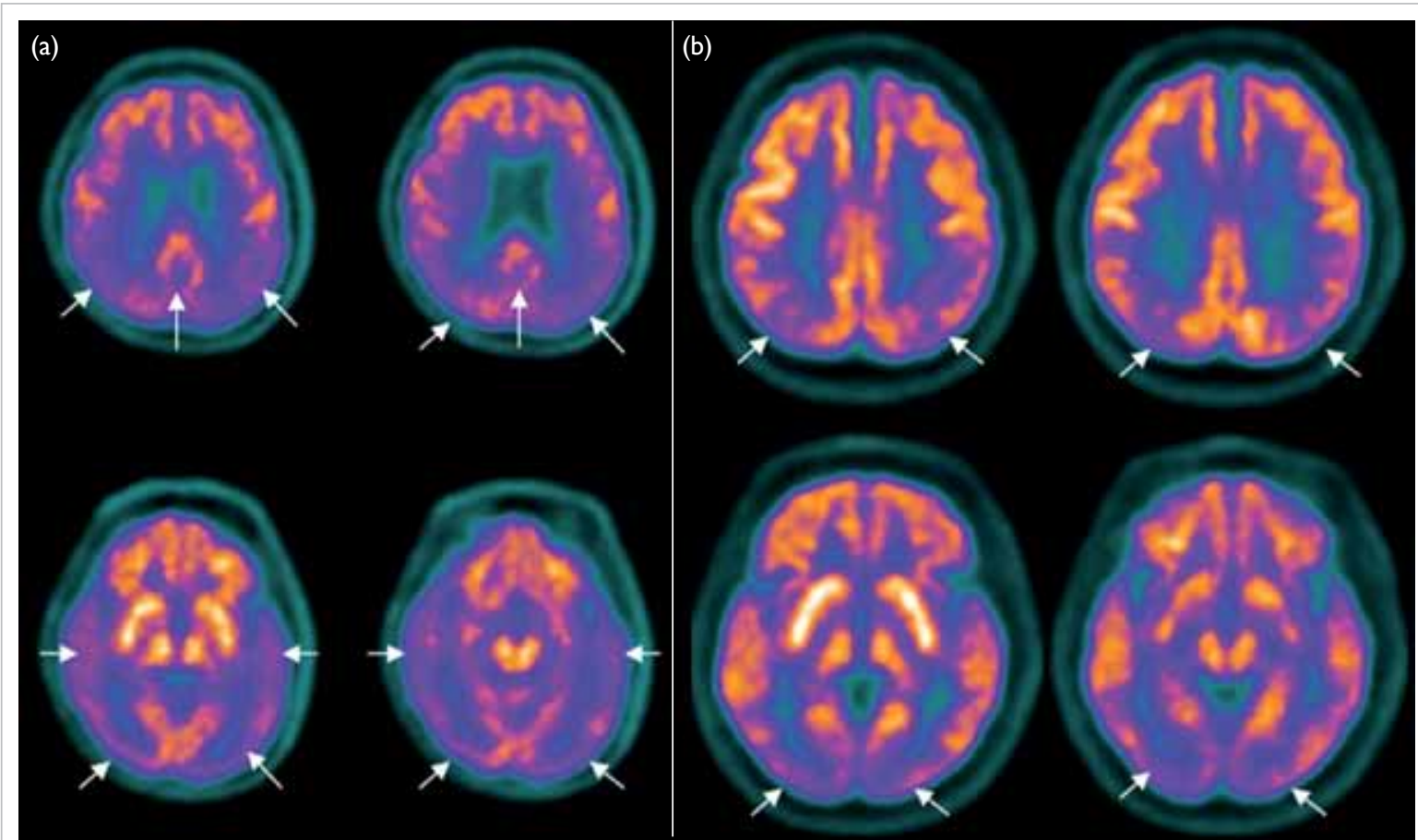

FIG. ${ }^{18}$ FDG-PET brain imaging of patients with LBD

(a) A patient with an AD pattern of hypometabolism over the bilateral temporoparietal and occipital lobes and posterior cingulate gyrus (arrows). (b) A patient without an AD pattern of hypometabolism; the hypometabolism occurred in mainly bilateral occipital lobes and mild hypometabolism over the bilateral parietal lobes (arrows)

Abbreviations: AD = Alzheimer's disease; ${ }^{18} \mathrm{FDG}$-PET = $\left[{ }^{18} \mathrm{~F}\right]$-2-fluoro-2-deoxy-D-glucose positron emission tomography; $\mathrm{LBD}=$ Lewy body dementia

TABLE I. Diagnostic criteria for DLB and PDD $1,2 *$

\section{McKeith criteria for DLB ${ }^{2}$}

Central feature (essential for possible or probable diagnosis)

- Meeting the diagnosis of dementia

- Deficits on tests of attention, executive function, and visuospatial ability may be especially prominent

Core features (two core features for probable and one for possible diagnosis)

- Fluctuating cognition, recurrent visual hallucination, spontaneous parkinsonism

Suggestive features (any suggestive features with at least 1 core feature, a probable diagnosis could be made; any suggestive feature in the absence of any core features defines a possible diagnosis)

- Rapid eye movement sleep behaviour disorder, severe neuroleptic sensitivity, low-dopamine transporter uptake in basal ganglia

Supportive features (commonly present but no proven diagnostic specificity)

- Repeated falls and syncope, transient, unexplained loss of consciousness, severe autonomic dysfunction, non-visual hallucination, systematised delusion, depression, relative preservation of medial temporal lobe structures, generalised low uptake on perfusion SPECT/PET scan with reduced occipital activity, low-uptake MIBG myocardial scintigraphy, prominent slow-wave activity on EEG with temporal lobe transient sharp waves

\section{Criteria for PDD 1}

Core features (both required for possible or probable diagnosis)

- Parkinson's disease diagnosed according to Queen Square Brain Bank criteria

- Dementia developed in the context of established Parkinson's disease

Associated clinical features (typical profile of cognitive deficits must be present for probable, but not possible diagnosis)

- Typical cognitive profile: impairment in at least two of the following domains: (1) attention, which may fluctuate, (2) executive function, (3) visuospatial function, (4) free recall that usually improves with cueing

- Presence of behavioural features supports but absence does not exclude the diagnosis; includes (1) apathy, (2) depressed or anxious mood, (3) hallucinations, (4) delusions, (5) excessive daytime sleepiness

Abbreviations: DLB = dementia with Lewy bodies; $\mathrm{EEG}=$ electroencephalogram; $\mathrm{MIBG}=$ metaiodobenzylguanidine myocardial scintigraphy; PDD =

Parkinson's disease dementia; PET = positron emission tomography; SPECT = single-photon emission computed tomography

* 'I-Year rule': In DLB, the onset of dementia occurs within 12 months of spontaneous parkinsonism. In PDD, dementia develops within the context of established Parkinson's disease (>12 months of spontaneous parkinsonism)

December 2015 were reviewed. This study was done in accordance with the principles outlined in the Declaration of Helsinki. Probable DLB was diagnosed according to McKeith criteria ${ }^{2}$ (Table $1^{1,2}$ ). Probable PDD was diagnosed according to the following: the patient should meet the diagnostic criteria of Queen Square Brain Bank criteria with dementia developing in the context of established Parkinson's disease with cognitive impairment in more than one domain and severe enough to impair daily life (Table 
$\left.1^{1,2}\right)$. The differentiation between DLB and PDD was based on temporal sequence of symptomsfor DLB, dementia developed before or within 1 year of parkinsonism (ie the clinical syndrome characterised by tremor, bradykinesia, rigidity, and postural instability); for PDD, dementia developed more than 1 year after the established diagnosis of Parkinson's disease. ${ }^{1}$ All patients underwent functional imaging in the form of ${ }^{18}$ FDG-PET or technetium-99m hexamethylpropylene amine oxime single-photon emission computed tomography (SPECT) that would show either hypometabolism or hypoperfusion of the occipital lobes, respectively. Data on baseline demographics, baseline and firstyear Mini-Mental State Examination (MMSE) score, ${ }^{9}$ Clinical Dementia Rating (CDR) score, ${ }^{10}$ ageadjusted Charlson Comorbidity Index, ${ }^{11}$ baseline Neuropsychiatric Inventory (NPI) score, ${ }^{12}$ baseline Barthel index $-20,{ }^{13}$ presenting cognitive symptoms, and BPSD were derived from clinical records. 'Time to diagnosis' was defined as the difference between the date of first presentation to the memory clinic and the date of first diagnosis of LBD. Patients with DLB were further classified as having an 'AD imaging pattern' if the functional imaging demonstrated bilateral temporoparietal hypometabolism or hypoperfusion with or without precuneus and posterior cingulate gyrus hypometabolism or hypoperfusion (Fig).,14

Clinical outcomes including falls, dysphagia, aspiration pneumonia, development of pressure sores, and mortality were traced. For patients with a history of falls, geriatric day hospital (GDH) training was traced including the pre-/post-training Elderly Mobility Scale ${ }^{15}$ and Berg Balance Scale. ${ }^{16}$
Parkinsonism medication was often titrated at the GDH. Dysphagia was further subclassified as oral or pharyngeal according to the clinical assessment by a speech therapist (ST) or, if available, a video fluoroscopic swallowing study (VFSS). ${ }^{17}$ Penetration was defined as barium material entering the airway but not passing below the vocal cords; aspiration was defined as barium material passing below the level of the vocal cords..$^{18}$ The locations of pressure sores and staging, according to National Pressure Ulcer Advisory Panel, ${ }^{19}$ were recorded. 'Time to event' was defined as the difference between the date of diagnosis and first appearance of these events.

\section{Statistical analyses}

Parametric variables were expressed as mean \pm standard deviation and non-parametric variables were expressed by median (interquartile range [IQR]). Descriptive statistics were used to express the frequency of defining features of LBD. Chi squared test or Fisher's exact test was used to compare categorical variables. Independent-samples $t$ test or Mann-Whitney $U$ test were used to compare continuous variables when appropriate. Statistical significance was inferred by a two-tailed $P$ value of $<0.05$. All statistical analyses were carried out using the Statistical Package for the Social Sciences (Windows version 18.0; SPSS Inc, Chicago [IL], United States).

\section{Results}

\section{Baseline demographics and clinical characteristics}

There were 23 patients with LBD (16 with DLB and 7

TABLE 2. Baseline demographics for patients with LBD

\begin{tabular}{|c|c|c|c|c|}
\hline & \multicolumn{3}{|c|}{ Mean \pm SD, No. (\%), or median (IQR) } & \multirow{2}{*}{$\begin{array}{c}\text { P value (DLB vs } \\
\text { PDD) }\end{array}$} \\
\hline & DLB $(n=16)$ & PDD $(n=7)$ & Overall $(n=23)$ & \\
\hline Age at presentation (years) & $76 \pm 7$ & $78 \pm 4$ & $76 \pm 7$ & $0.37^{*}$ \\
\hline Female & $4(25)$ & $3(43)$ & $7(30)$ & $0.63 \dagger$ \\
\hline Years of education & $8 \pm 5$ & $8 \pm 4$ & $8 \pm 5$ & $0.80^{\star}$ \\
\hline Baseline MMSE score & $18 \pm 8$ & $19 \pm 6$ & $19 \pm 7$ & $0.81^{*}$ \\
\hline First-year MMSE score & $18 \pm 9$ & $19 \pm 6$ & $18 \pm 8$ & $0.71^{*}$ \\
\hline Age-adjusted CCI & $5(4-6)$ & $5(4-7)$ & $5(4-6)$ & $0.67 \ddagger$ \\
\hline CDR score & $1(0.5-2)$ & $1(0.5-1)$ & $1(0.5-1)$ & $0.62 \ddagger$ \\
\hline NPI score & $9(3-15)[n=13]$ & $8(5-31)[n=5]$ & $9(3-15)[n=18]$ & $0.78 \ddagger$ \\
\hline Time to diagnosis (days) & $45(3-250)$ & $402(0-1384)$ & $111(0-777)$ & $0.28 \ddagger$ \\
\hline Accurate pre-imaging diagnosis & $9(56)$ & $3(43)$ & $12(52)$ & $0.67 \dagger$ \\
\hline
\end{tabular}

Abbreviations: $\mathrm{CCl}=$ Charlson Comorbidity Index; CDR = Clinical Dementia Rating; $\mathrm{DLB}=$ dementia with Lewy bodies; $I \mathrm{QR}=$ interquartile range; $\mathrm{LBD}=$ Lewy body dementia; MMSE = Mini-Mental State Examination; NPI = Neuropsychiatric Inventory; PDD =

Parkinson's disease dementia; SD = standard deviation

* Independent-samples $t$ test

+ Chi squared test

‡ Mann-Whitney $U$ test 
with PDD). The mean age at presentation was $76 \pm 7$ years and the mean MMSE score at presentation was $19 \pm 7$ with a total duration of follow-up of 72 patientyears (mean follow-up, $1138 \pm 698$ days). The baseline demographics of the patients are summarised in Table 2. There was no statistically significant difference in baseline demographics between DLB and PDD patients. The time to diagnosis appeared to be longer but not statistically significant for PDD patients, possibly due to very small numbers in the two groups. The overall accuracy of diagnosis was $52 \%$. Six (38\%) of the 16 DLB patients were initially misdiagnosed as AD. The frequency of defining clinical characteristics of LBD among DLB and PDD patients is summarised in Table 3 . There were no statistically significant differences (results not shown). Of note, $69 \%$ of DLB patients presented with parkinsonism and $74 \%$ of LBD patients had vivid visual hallucinations. Information about the content of visual hallucinations was available for 14 of 17 patients: $50 \%(\mathrm{n}=7)$ involved persons, $7 \%$ $(n=1)$ involved objects, $21 \%(n=3)$ a combination of persons and animals, 7\% $(\mathrm{n}=1)$ a combination of insects and animal, 7\% ( $n=1)$ a combination of insects and objects, and 7\% $(\mathrm{n}=1)$ a combination of animal and objects. An NPI score was available for $78 \%(18 / 23)$ at baseline, of whom $83 \%(15 / 18)$ had a score of $\geq 1$, and $78 \%(14 / 18)$ had at least one NPI subcategory rated as severe, ie $\geq 4$. The three most common BPSD as indicated by a NPI score of $\geq 1$ were visual hallucination (56\%), anxiety $(50 \%)$, and apathy (50\%). There was no significant difference in BPSD in terms of NPI score for DLB and PDD patients (results not shown).

\section{Falls}

Of the patients, $16(70 \%)$ had a total of 23 falls (all non-syncopal) with four complicated by bone fractures and two associated with intracerebral haemorrhage. The event rate was 0.32 per personyears. Ten patients underwent GDH training after their fall(s). The median time to first GDH training (from the time of diagnosis) was 56 (IQR, 56-663) days with a mean time of $93 \pm 44$ days. Pairedsamples $t$ test did not identify any significant pre- $/$ post-training difference in Elderly Mobility Scale ${ }^{15}$ or Berg Balance Scale ${ }^{16}$ scores $(10 \pm 4$ vs $11 \pm 5$, $\mathrm{P}=0.81$ and $25 \pm 13$ vs $25 \pm 14, \mathrm{P}=1.0$, respectively). Comparison of LBD patients with and without a fall history revealed no significant difference in clinical features (including visual hallucination, parkinsonism, and fluctuation of consciousness) or medication (including benzodiazepine or antipsychotics) [results not shown]. Parkinsonism was numerically more prevalent among fallers $(88 \%$ vs $57 \%$; $\mathrm{P}=0.14$ ).

\section{Dysphagia and aspiration pneumonia}

Of the patients, six (26\%) had a total of 13 episodes of pneumonia, and $12(52 \%)$ had dysphagia. The mean time to first episode of aspiration pneumonia was $866 \pm 689$ days (median, 634; IQR, 315-1456 days; $n=6$ ) and to first diagnosis of dysphagia $951 \pm$ 734 days (median, 862; IQR, 311-1624 days; $\mathrm{n}=12$ ). Five patients underwent VFSS (time to VFSS: 831 \pm 728; median, 723; IQR, 154-1562 days). Three of four patients with penetration developed aspiration pneumonia; both patients with aspiration on VFSS developed aspiration pneumonia. The event rates were 0.17 and 0.18 per person-years for dysphagia and aspiration pneumonia, respectively. Patients with LBD with a history of aspiration pneumonia compared with those without were more likely to have been identified by the ST to have dysphagia ( $100 \%$ vs $35 \%$; $\mathrm{P}=0.01$ ), oral dysphagia ( $83 \%$ vs $29 \%$; $\mathrm{P}=0.04$ ), pharyngeal dysphagia ( $83 \%$ vs $29 \% ; \mathrm{P}=0.04$ ), or dysphagia that required Ryle's tube insertion $(67 \%$ vs $12 \% ; \mathrm{P}=0.02$ ) [Table 4].

\section{Pressure sores}

Six (26\%) patients developed pressure sores with four over the sacrum and two over the heel (two in stage 1 , two in stage 3 , and two in stage 4). The mean time to development of pressure sore was $978 \pm 599$ days (median, 994; IQR, 379-1528 days). The event rate was 0.08 per person-years. A comparison between

TABLE 3. Frequency of defining clinical characteristics of Lewy body dementia at the time of initial presentation

\begin{tabular}{lccc}
\hline Clinical characteristic & \multicolumn{3}{c}{ No. (\%) of patients } \\
\cline { 2 - 4 } & DLB (n=16) & PDD (n=7) & Overall $(\mathbf{n}=\mathbf{2 3})$ \\
\hline Parkinsonism & $11(69)$ & $7(100)$ & $18(78)$ \\
Fluctuating cognition & $7(44)$ & $1(14)$ & $8(35)$ \\
Vivid visual hallucination & $12(75)$ & $5(71)$ & $17(74)$ \\
Neuroleptic sensitivity & $2(13)$ & 0 & $2(9)$ \\
REM sleep behaviour disorder & $9(56)$ & $2(29)$ & $11(48)$ \\
Postural hypotension & $1(6)$ & $1(14)$ & $2(9)$ \\
\hline
\end{tabular}

Abbreviations: DLB = dementia with Lewy bodies; PDD = Parkinson's disease dementia; REM = rapid eye movement 
TABLE 4. Comparison of clinical features in LBD patients with and without aspiration pneumonia

\begin{tabular}{|c|c|c|c|}
\hline \multirow[t]{2}{*}{ Clinical feature } & \multicolumn{2}{|c|}{ Mean \pm SD, No. (\%), or median (IQR) } & \multirow[t]{2}{*}{$P$ value } \\
\hline & $\begin{array}{l}\text { With aspiration } \\
\text { pneumonia }(n=6)\end{array}$ & $\begin{array}{l}\text { Without aspiration } \\
\text { pneumonia }(n=17)\end{array}$ & \\
\hline Age of presentation (years) & $75 \pm 7$ & $77 \pm 7$ & $0.60^{*}$ \\
\hline Female & $2(33)$ & $5(29)$ & $1.0 \dagger$ \\
\hline Baseline MMSE score & $19 \pm 6$ & $18 \pm 9$ & $0.62^{*}$ \\
\hline First-year MMSE score & $19 \pm 7$ & $16 \pm 10$ & $0.42^{*}$ \\
\hline Baseline CDR score & $1(1-1.5)$ & $0.5(0.5-1.0)$ & $0.26 \ddagger$ \\
\hline Baseline age-adjusted $\mathrm{CCl}$ & $5(4-7)$ & $5(4-6)$ & $0.87 \ddagger$ \\
\hline Baseline total NPI score & $8(5-21)[n=5]$ & $9(3-21)[n=13]$ & $0.63 \ddagger$ \\
\hline Parkinsonism & $5(83)$ & $13(76)$ & $1.0 \dagger$ \\
\hline Fluctuating cognition & $1(17)$ & $7(41)$ & $0.40 \dagger$ \\
\hline On antipsychotics & 0 & $3(18)$ & $0.54 \dagger$ \\
\hline On benzodiazepine & 0 & $6(35)$ & $0.14 \dagger$ \\
\hline On hypnotics & 0 & $2(12)$ & $1.0 \dagger$ \\
\hline On levodopa & $2(33)$ & $9(53)$ & $0.64 \dagger$ \\
\hline On anticholinesterase inhibitors & $3(50)$ & $13(76)$ & $0.32 \dagger$ \\
\hline ST assessment with dysphagia & $6(100)$ & $6(35)$ & $0.01 \dagger$ \\
\hline ST assessment with oral dysphagia & $5(83)$ & $5(29)$ & $0.04 \dagger$ \\
\hline ST assessment with pharyngeal dysphagia & $5(83)$ & $5(29)$ & $0.04 \dagger$ \\
\hline Dysphagia that recommended Ryle's tube insertion & $4(67)$ & $2(12)$ & $0.02 \dagger$ \\
\hline
\end{tabular}

Abbreviations: $\mathrm{CCl}=$ Charlson Comorbidity Index; $\mathrm{CDR}=$ Clinical Dementia Rating; IQR = interquartile range; $\mathrm{LBD}=$ Lewy body dementia; MMSE = Mini-Mental State Examination; NPI = Neuropsychiatric Inventory; SD = standard deviation; ST = speech therapist

* Independent-samples $t$ test

+ Chi squared test

$\ddagger$ Mann-Whitney $U$ test

LBD patients with or without pressure sores did not identify any significant difference in clinical features (results not shown).

\section{Mortality}

Seven (30\%) patients died of various diseases: three $(43 \%)$ of pneumonia, two (29\%) of unexplained cardiac arrest (UCA), and one (14\%) each of pressure sore sepsis and choking. The mean time to death was $894 \pm 617$ days (median, 798; IQR, 312-1597 days). The event rate was 0.10 per person-years. Deceased patients with LBD, compared with alive patients, scored a higher presenting CDR (median [IQR]: 1 [1-2] vs 0.5 [0.5-1.0]; $\mathrm{P}=0.01)$, lower mean baseline Barthel index ( $13 \pm 7$ vs $18 \pm 4 ; \mathrm{P}=0.04)$, and were more likely to have been prescribed levodopa (86\% vs $31 \% ; \mathrm{P}=0.03)$.

\section{Alzheimer's disease pattern of functional imaging}

Of the patients, 19 underwent ${ }^{18}$ FDG-PET and four underwent perfusion SPECT imaging. Twelve patients (9 DLB and 3 PDD) had an AD pattern of functional imaging: all had bilateral temporoparietal lobe hypometabolism/hypoperfusion; three concomitantly had hypoperfusion/hypometabolism over the posterior cingulate gyrus and one had additional hypometabolism over the precuneus. Patients with LBD with an AD pattern of functional imaging compared with those without were younger at presentation ( $73 \pm 6$ vs $80 \pm 6$ years; $P=0.02)$ and had a lower MMSE score at 1 year ( $15 \pm 8$ vs $22 \pm 6$; $\mathrm{P}=0.05)$. There was no difference in the presentation of visual hallucination between the two groups of patients (Table 5).

\section{Discussion}

An accurate diagnosis of LBD is important. It allows prescription of acetylcholinesterase inhibitors or avoidance of antipsychotics in view of the risk of neuroleptic sensitivity. An overall accuracy of clinical diagnosis of $52 \%$ in our study is similar to findings in western studies, eg $62 \%$ by a neurologist. ${ }^{20}$ Our results reveal that no single diagnostic criteria or test is infallible and the diagnosis needs follow-up review and support from functional imaging when 
TABLE 5. Comparison of clinical features in LBD patients with and without Alzheimer's disease pattern of hypoperfusion/ hypometabolism on SPECT or ${ }^{18}$ FDG-PET

\begin{tabular}{|c|c|c|c|}
\hline \multirow[t]{2}{*}{ Clinical feature } & \multicolumn{2}{|c|}{ Mean \pm SD, No. (\%), or median (IQR) } & \multirow[t]{2}{*}{$P$ value } \\
\hline & $\begin{array}{l}\text { Without AD pattern } \\
\qquad(n=11)\end{array}$ & $\begin{array}{l}\text { With AD pattern } \\
(n=12)\end{array}$ & \\
\hline Age of presentation (years) & $80 \pm 6$ & $73 \pm 6$ & $0.02^{*}$ \\
\hline Female & $4(36)$ & $3(25)$ & $0.67 \dagger$ \\
\hline Baseline MMSE score & $21 \pm 6$ & $16 \pm 8$ & $0.13^{*}$ \\
\hline First-year MMSE score & $22 \pm 6$ & $15 \pm 8$ & $0.05^{\star}$ \\
\hline Baseline CDR score & $1(0.5-1.0)$ & $1(0.5-2)$ & $0.60 \ddagger$ \\
\hline Baseline $\mathrm{CCl}$ & $5(4-6)$ & $4(4-7)$ & $0.53 \ddagger$ \\
\hline Baseline total NPI score & $12(7-22)[n=9]$ & $8(2-18)[n=9]$ & $0.26 \ddagger$ \\
\hline Baseline Barthel index & $19 \pm 3$ & $15 \pm 6$ & $0.15^{\star}$ \\
\hline Fluctuating cognition & $5(45)$ & $3(25)$ & $0.40 \dagger$ \\
\hline Parkinsonism & $8(73)$ & $10(83)$ & $0.64 \dagger$ \\
\hline Recurrent visual hallucination & $8(73)$ & $10(83)$ & $0.64 \dagger$ \\
\hline REM sleep behaviour disorder & $7(64)$ & $4(33)$ & $0.22 \dagger$ \\
\hline With dysexecutive syndrome & $1(9)$ & $6(50)$ & $0.07 \dagger$ \\
\hline On antipsychotics & $6(55)$ & 0 & $0.09 \dagger$ \\
\hline On levodopa & $6(55)$ & $5(42)$ & $0.53 \dagger$ \\
\hline History of falls & $7(64)$ & $9(75)$ & $0.67 \dagger$ \\
\hline History of dysphagia & $6(55)$ & $6(50)$ & $0.27 \dagger$ \\
\hline History of aspiration pneumonia & $1(9)$ & $5(42)$ & $0.16 \dagger$ \\
\hline History of pressure sore & $3(27)$ & $3(25)$ & $1.0 \dagger$ \\
\hline Old-age-home resident & $5(45)$ & $4(33)$ & $0.68 \dagger$ \\
\hline
\end{tabular}

Abbreviations: $\mathrm{AD}=$ Alzheimer's disease; $\mathrm{CCl}=$ Charlson Comorbidity Index; CDR = Clinical Dementia Rating; ${ }^{18}$ FDG-PET =

$\left[{ }^{18} \mathrm{~F}\right]$-2-fluoro-2-deoxy-D-glucose positron emission tomography; IQR = interquartile range; LBD = Lewy body dementia; MMSE =

Mini-Mental State Examination; NPI = Neuropsychiatric Inventory; REM = rapid eye movement; SD = standard deviation; SPECT =

single-photon emission computed tomography

* Independent-samples $t$ test

$\dagger$ Chi squared test

$\neq$ Mann-Whitney $U$ test

appropriate. In our series, $38 \%$ of DLB patients were initially misdiagnosed as AD. This is thought to have been related to the presence of amnesia in all patients at initial presentation: only $69 \%$ of DLB patients presented with parkinsonism. There was no difference in the clinical features of DLB and PDD patients. Braak et $\mathrm{al}^{21}$ have proposed a pathological staging of Parkinson's disease with Lewy body pathology starting in the dorsal IX/X motor nucleus or adjoining intermediate reticular zone, and spreading rostrally in the brainstem then to the limbic system and subsequently to the neocortex with the underlying mechanism being the spread of $\alpha$-synuclein from cell to cell. This might explain why DLB and PDD can progress and later overlap clinically.

Compared with the previous literature review of Chinese LBD case reports (1980-2012) by Han et $\mathrm{al}^{4}$ including $31 \mathrm{DLB}$ and four PDD patients with a younger mean age of onset (67 \pm 10 years), more patients in our series presented with cognitive decline (100\% vs $60 \%)$, parkinsonism (78\% vs $9 \%$ ), visual hallucinations ( $74 \%$ vs $9 \%)$, and rapid eye movement sleep behaviour disorder (48\% vs $11 \%$ ). These differences may be related to the heightened awareness of the core features of LBD among Chinese doctors in recent years or because patients in our series presented at a more advanced stage of dementia (Han et $\mathrm{al}^{4}$ did not state the severity of dementia). Nonetheless, both case series reported similar rates of postural hypotension ( $9 \%$ vs $3 \%$ ) and BPSD ( $83 \%$ vs $86 \%) .{ }^{4}$ The rate of postural hypotension in both case series is much lower than that reported in other literature on DLB patients, ie $50 \%{ }^{22}$ The lower rates of postural hypotension may be related to under-recognition. Similar to our findings, in a study of 22 Chinese DLB patients (mean age, $74 \pm 8$ years; mean MMSE score, $16 \pm 7$; mean NPI score, $24 \pm 16$ ), 
three most commonly observed BPSDs were visual hallucinations (86\%), delusions (64\%), and anxiety (59\%); total NPI score was an independent predictor of caregiver burden (odds ratio $=1.537 ; \mathrm{P}=0.048$ ). ${ }^{22}$ Clinicians should pay particular attention to BPSD, particularly visual hallucinations and anxiety symptoms, when managing Chinese LBD patients.

In addition, falls, dysphagia, and pressure sores can contribute to carer stress but they were not included in previous studies of LBD patients. ${ }^{23,24}$ Nearly $70 \%$ of our LBD patients experienced falls. This rate is greater than the previously reported rates of $11 \%$ to $44 \%{ }^{25,26}$ Although visuospatial impairment, cognitive fluctuation, parkinsonism, or visual hallucinations were proposed as possible mechanisms that contributed to falls, only parkinsonism was identified in one study of $51 \mathrm{AD}$ and 27 DLB patients as an independent risk factor. ${ }^{25,26}$ Because of the limited sample size, no significant risk factors could be identified in our series. With regard to the finding of limited improvement in mobility after GDH training, it is likely that many factors affect the mobility of LBD patients. These factors include dementia, postural hypotension, and poor balance from disease. Clinicians should alert carers of the risk of falls and offer advice about general measures for falls prevention, including addressing environmental risk factors and use of safety alarms. Compared with Londos et al's finding ${ }^{17}$ that $29 \%$ of $82 \mathrm{LBD}$ patients (median age, 77 years; median MMSE score, 20) had dysphagia on VFSS, we reported a higher rate of $52 \%$. When identified by STs, LBD patients and their carers should be given advice about diet modification (eg use of thickeners) and postural changes (eg chin tuck). In addition, clinicians should titrate the levodopa dose as far as possible. $^{27}$

Given that LBD is an irreversible neurodegenerative disease, advance care planning (ACP) forms a major part of care. ${ }^{28}$ Our data for dysphagia, aspiration pneumonia, pressure sores, and mortality can offer useful information during ACP for Chinese LBD patients. Since those patients who have died had a higher presenting CDR score, lower Barthel Index, and greater usage of levodopa (which probably reflects more severe parkinsonism), ACP should be initiated earlier in LBD patients with these features. It has been reported that LBD patients can have UCA and in our series two (28.6\%) patients died of UCA. Unexplained cardiac arrest is proposed to be related to pathological involvement of the intermediolateral columns of the spinal cord, autonomic ganglia, and sympathetic neurons, affecting either respiration or heart rhythm. ${ }^{29}$ Such risk of UCA should be explained during ACP. Presence of hypometabolism/hypoperfusion over the temporoparietal lobes/precuneus/posterior cingulate gyrus was used as surrogate markers of concomitant AD pathologies in our LBD patients. As far as we are aware, this is the first study to show that concomitant AD pathologies among Chinese LBD patients can result in an early age of presentation or diagnosis and lower MMSE score at 1 year. Our findings provide further evidence of the synergistic contribution of AD pathologies to LBD dementia. ${ }^{6}$

This study has several limitations. It was a single-centre retrospective case series, therefore, we considered clinical features only as present or absent when clearly stated as such. This might have affected our results. Pathological diagnosis was not obtained including pathological proof of concomitant $\mathrm{AD}$ pathologies. Since all subjects were recruited from the memory clinic, LBD patients who present to a psychiatric clinic may be different, eg with more BPSD or visual hallucinations. The severity of parkinsonism was not graded so the influence of parkinsonism on long-term outcomes such as falls or aspiration pneumonia was not fully analysed. Although our case series comprised the largest number of Chinese patients with LBD supported by functional imaging, the number remained limited. Our findings should be confirmed by a larger study with Pittsburgh compound B imaging to delineate the concomitant presence of amyloid plaques.

\section{Conclusions}

Falls, dysphagia, aspiration pneumonia, and pressure sores were common among LBD patients. Lewy body dementia patients with an AD pattern of neuroimaging had an earlier age of diagnosis or presentation and lower 1-year MMSE scores. Such information is useful in the formulation of a management plan for Chinese LBD patients.

\section{Declaration}

All authors have disclosed no conflicts of interest.

\section{References}

1. Walker Z, Possin KL, Boeve BF, Aarsland D. Lewy body dementias. Lancet 2015;386:1683-97.

2. McKeith IG, Dickson DW, Lowe J, et al. Diagnosis and management of dementia with Lewy bodies: third report of the DLB consortium. Neurology 2005;65:1863-72.

3. Shea YF, Ha J, Lee SC, Chu LW. Impact of ${ }^{18}$ FDG PET and ${ }^{11} \mathrm{C}$-PIB PET brain imaging on the diagnosis of Alzheimer's disease and other dementias in a regional memory clinic in Hong Kong. Hong Kong Med J 2016;22:327-33.

4. Han D, Wang Q, Gao Z, Chen T, Wang Z. Clinical features of dementia with lewy bodies in 35 Chinese patients. Transl Neurodegener 2014;3:1.

5. Valkanova V, Ebmeier KP. Neuroimaging in dementia. Maturitas 2014;79:202-8.

6. Gomperts SN. Imaging the role of amyloid in PD dementia and dementia with Lewy bodies. Curr Neurol Neurosci Rep 2014;14:472.

7. Chiba Y, Fujishiro H, Ota K, et al. Clinical profiles of dementia with Lewy bodies with and without Alzheimer's 
disease-like hypometabolism. Int J Geriatr Psychiatry 2015;30:316-23.

8. Killen A, Flynn D, De Brún A, et al. Support and information needs following a diagnosis of dementia with Lewy bodies. Int Psychogeriatr 2016;28:495-501.

9. Chiu FK, Lee HC, Chung WS, Kwong PK. Reliability and validity of the Cantonese version of Mini-Mental State Examination: a preliminary study. J Hong Kong Coll Psychiatr 1994;4(2 Suppl):S25-8.

10. Morris JC. The Clinical Dementia Rating (CDR): current version and scoring rules. Neurology 1993;43:2412-4.

11. Charlson ME, Pompei P, Ales KL, MacKenzie CR. A new method of classifying prognostic comorbidity in longitudinal studies: development and validation. J Chronic Dis 1987;40:373-83.

12. Cummings JL, Mega M, Gray K, Rosenberg-Thompson S, Carusi DA, Gornbein J. The Neuropsychiatric Inventory: comprehensive assessment of psychopathology in dementia. Neurology 1994;44:2308-14.

13. Collin C, Wade DT, Davies S, Horne V. The Barthel ADL Index: a reliability study. Int Disabil Stud 1988;10:61-3.

14. McKhann GM, Knopman DS, Chertkow H, et al. The diagnosis of dementia due to Alzheimer's disease: recommendations from the National Institute on AgingAlzheimer's Association workgroups on diagnostic guidelines for Alzheimer's disease. Alzheimers Dement 2011;7:263-9.

15. Smith R. Validation and reliability of the Elderly Mobility Scale. Physiotherapy 1994;80:744-7.

16. Berg KO, Wood-Dauphinee SL, Williams JI, Maki B. Measuring balance in the elderly: validation of an instrument. Can J Public Health 1992;83 Suppl 2:S7-11.

17. Londos E, Hanxsson O, Alm Hirsch I, Janneskog A, Bülow M, Palmqvist S. Dysphagia in Lewy body dementia-a clinical observational study of swallowing function by videofluoroscopic examination. BMC Neurol 2013;13:140.

18. Rosenbek JC, Robbins JA, Roecker EB, Coyle JL, Wood JL. A penetration-aspiration scale. Dysphagia 1996;11:93-8.

19. National Pressure Ulcer Advisory Panel. NPUAP pressure injury stages. Available from: http://www.npuap.org/ resources/educational-and-clinical-resources/npuappressure-injury-stages/. Accessed 7 May 2016.

20. Galvin JE. Improving the clinical detection of Lewy body dementia with the Lewy body composite risk score. Alzheimers Dement (Amst) 2015;1:316-24.

21. Braak H, Del Tredici K, Rüb U, de Vos RA, Jansen Steur EN, Braak E. Staging of brain pathology related to sporadic Parkinson's disease. Neurobiol Aging 2003;24:197-211.

22. Takemoto M, Sato K, Hatanaka N, et al. Different clinical and neuroimaging characteristics in early stage Parkinson's disease with dementia and dementia with Lewy bodies. J Alzheimers Dis 2016;52:205-11.

23. Liu S, Jin Y, Shi Z, et al. The effects of behavioral and psychological symptoms on caregiver burden in frontotemporal dementia, Lewy body dementia, and Alzheimer's disease: clinical experience in China. Aging Ment Health 2016 Feb 16:1-7. Epub ahead of print.

24. Leggett AN, Zarit S, Taylor A, Galvin JE. Stress and burden among caregivers of patients with Lewy body dementia. Gerontologist 2011;51:76-85.

25. Imamura T, Hirono N, Hashimoto M, et al. Fall-related injuries in dementia with Lewy bodies (DLB) and Alzheimer's disease. Eur J Neurol 2000;7:77-9.

26. Kudo Y, Imamura T, Sato A, Endo N. Risk factors for falls in community-dwelling patients with Alzheimer's disease and dementia with Lewy bodies: walking with visuocognitive impairment may cause a fall. Dement Geriatr Cogn Disord 2009;27:139-46.

27. Alagiakrishnan K, Bhanji RA, Kurian M. Evaluation and management of oropharyngeal dysphagia in different types of dementia: a systematic review. Arch Gerontol Geriatr 2013;56:1-9.

28. Jethwa KD, Onalaja O. Advance care planning and palliative medicine in advanced dementia: a literature review. BJPsych Bull 2015;39:74-8.

29. Molenaar JP, Wilbers J, Aerts MB, et al. Sudden death: an uncommon occurrence in dementia with Lewy bodies. J Parkinsons Dis 2016;6:53-5. 